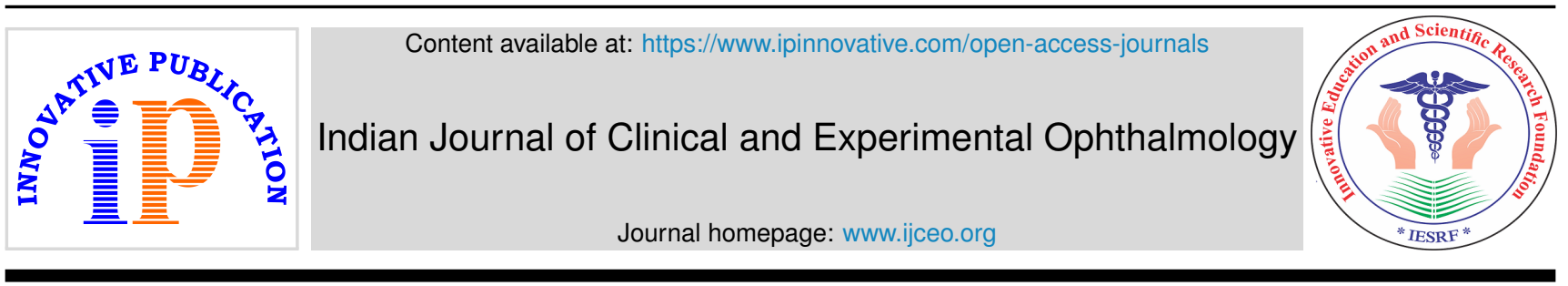

Original Research Article

\title{
A study on digital eye strain among patients attending at one of the tertiary care hospitals of Saurashtra region, Gujarat
}

\author{
Varsha M Modi ${ }^{1}$,* \\ ${ }^{1}$ Dept. of Ophthalmology, Shantabaa Medical College, Amreli, Gujarat, India
}

\section{A R T I C L E I N F O}

\section{Article history:}

Received 11-12-2020

Accepted 15-12-2020

Available online 30-06-2021

\section{Keywords:}

Digital eye strain (DES)

Optical aid

Risk factors

Visual fatigue

\begin{abstract}
A B S T R A C T
Background: Digital Eye Strain (DES) is a group of eye and vision-related problems that result from prolonged computer, tablet, e-reader and cell phone use. Majority of scientific literature available for DES has targeted only youth/young people, overlooking rest age-groups.

Aim of this study was to assess the prevalence of DES and its various risk factors of digital device usage pattern and to correlate them statistically with clinical features.

Methodology: The study was conducted at medical college attached hospital in Amreli district, Gujarat, India during June - September 2020. Total 320 study participants were included in research. All patients attending ophthalmic OPD during study -period were screened for DES related symptoms and history of digital device usage. Information collected for socio-demographic profile, pattern of device usage and reported clinical features. Data were entered in MS Excel and analyzed through SPSS software.

Result: Majority of study participants (47.81\%) belonged to 18-30 years' age-group, 186(58.13\%) were males. Major symptoms of DES reported were: Headache (77.81\%) dry-eye (61.56\%), Temporary Difficulty in gaze (51.25\%), Red-eye (49.37\%) and blurred vision (44.68\%). Of total, $59.06 \%$ and $9.06 \%$ respectively used digital device for 4-6 hours and $>6$ hours per day. Approximate screen distance $<50 \mathrm{~cm}$. from eyes was preferred by $192(60 \%)$ participants. Bright contrast setting was preferred by majority (253, $79.05 \%)$. Taking break after 30 minutes of continuous usage was preferred by 84 (26.25\%) participants. Conclusion: Role of age and gender was found statistically significant in occurrence of many of symptoms of DES. Approximate distance of digital device from eyes revealed significant association with burning, dry and red eyes, headache and temporary difficulty in gaze. Taking preferred break after 30 minutes of continuous usage of digital device, all clinical symptoms revealed significant association except double vision. Dry eyes, temporary difficulty in gaze and blurred vision revealed comparatively more risk with pattern optical aid usage.

(C) This is an open access article distributed under the terms of the Creative Commons Attribution License (https://creativecommons.org/licenses/by/4.0/) which permits unrestricted use, distribution, and reproduction in any medium, provided the original author and source are credited.
\end{abstract}

\section{Introduction}

The terms visual fatigue (VF) and computer vision syndrome (CVS) are used alternatively with digital eye strain (DES). It describes a group of eye and vision-related problems that result from prolonged computer, tablet, ereader and cell phone use. Many individuals experience eye discomfort and vision problems when viewing digital screens for extended periods. The level of discomfort

\footnotetext{
* Corresponding author.

E-mail address: dr.varshamayankmodi@gmail.com (V. M. Modi).
}

appears to increase with the amount of digital screen use. ${ }^{1}$ Viewing a computer or digital screen often makes the eyes work harder. Uncorrected vision problems can increase the severity of computer vision syndrome (CVS) or digital eye-strain symptoms. Viewing a computer or digital screen is different than reading a printed page. Often the letters on the computer or handheld device are not as precise or sharply defined, the level of contrast of the letters to the background is reduced, and the presence of glare and reflections on the screen may make viewing difficult. ${ }^{2}$ Eye focusing and eye movement requirements for digital screen 
viewing can place additional demands on visual system. In addition, the presence of even minor vision problems can often significantly affect comfort and performance while using digital screen devices. Uncorrected or under corrected vision problems can be major contributing factors to computer-related eyestrain. ${ }^{2}$

As per definition given by American optometric Association, the CVS is "a complex of eye and vision problem related to activities, which stress the near vision and which are experienced in relation or during the use of computer. Blurred vision, dry eyes, burning sensation, redness of eyes and headache are the main symptoms resulting from improper use of computers. ${ }^{3}$ In most cases, symptoms of CVS occur because the visual demands of the task exceed the visual abilities of the individual to comfortably perform them. At greatest risk for developing CVS are those persons who spend two or more continuous hours at a computer or using a digital screen device every day. ${ }^{2}$ The usage of digital devices might be correlated to the increasing prevalence of asthenopia. ${ }^{3}$ The consequences of asthenopia can also interfere significantly with attention and academic performance and can limit work capacity making it a real public health concern. ${ }^{4,5}$

In current era of digitalization, all professions including teaching are also being done online through using various instruments like computers desktop, laptop, tablets or mobiles. Due to easy availability of internet and also as a part of entertainment various social media are being explored by these devices. Almost all age-groups are using such device, even children under-five or geriatric people are also habituated to use frequently digital device for many hours in a day without knowing the side effects particularly eye, posture and psychological effects of long-lasting use of such devices. There is utmost need to create awareness through appropriate health education among all age-group people about hazards of long lasting uninterrupted digital device usage or screen time and measures to avoid them

Majority of the scientific literature available for DES has targeted only youth/young people, overlooking the rest agegroups. In current era, all age-group people are using digital devices for prolonged duration for both work-related and non work-related purposes. In current research, it is tried to include all age-group $>18$ years and to study the distribution of various risk factors and clinical features of DES among them. This would give an idea about the extent of the problem and also help in creating awareness and to suggest recommendations to avoid this health hazard amongst the digital device users.

This study aims to assess the frequency of symptoms of digital eye strain (DES) among patients attending one of the tertiary care hospitals at Saurashtra region of Gujarat state in India. The secondary objectives were: to study the prevalence of various risk factors in terms of practices of digital device usage pattern and to correlate them statistically with the clinical features.

\section{Materials and Methods}

The present study was conducted at one of the medical college attached hospital at Amreli district of Saurashtra region of Gujarat, India. After obtaining necessary ethical clearance from institutional committee, the study was conducted during June - September 2020. The study was a cross-sectional type and study participants were patients attending Ophthalmology OPD of the institute. The sample size was calculated using sample size calculation formula $4 \mathrm{pq} / \mathrm{E}^{2} .{ }^{6}$ The $\mathrm{p}$, i.e. prevalence of the positive character, symptomatic DES was taken as $56 \%$ (55.83\%) form the similar research conducted by Khan A et al. ${ }^{7}$ at southern India. Allowable error was taken as $10 \%$ and final calculated sample size came to 314 . Finally total 320 study participants were included in research.

All patients attending OPD of the institute during study duration were screened for DES related symptoms and history of digital device usage after excluding other probable causes for similar symptoms, the participants included in study with following characteristics:> 18 years of age and were having symptoms related to DES were asked for oral informed consent and if permitted, were included in the study. Those who did not give the informed consent to participate in study were excluded. Patients suffering from any of the following pre-existing conditions were excluded from study: any kind of eye infection/inflammation, squint, high myopia (more than 6.0 diopters), cataract, any variety of glaucoma, any retinal pathology or with history of any eye surgery. As headache was included as a symptom of DES, all patients with known cause of headache (e.g., migraine) were also excluded from study. After applying exclusion criteria and primarily screening for DES, all suitable patients were included in study till the desired sample size was met. Patients were selected through purposive sampling. The data collection was continued for selected participants till the calculated sample size achieved.

The pre-validated questionnaire was filled in by investigator by personal interview of the study participants. The various aspects for which information collected were socio-demographic profile, time spent for digital device (desktop, laptop, tablet, mobile etc.) used in a day, pattern of device usage, approximate distance of device from eyes and frequency of halt while using digital devices. The data were entered in MS Excel and analyzed through SPSS software. Frequency, Chi-square test and odds' ratio were applied as test of significance for statistical analysis of data and interpreted as significant if $\mathrm{p}$ value $<0.05$ was found. 


\section{Result}

As calculated sample size, 320 questionnaires were filled in and data were entered and analysed as per methodology. The basic socio-demographic details of study participants are described in Table 1.

The majority of study participants (153, 47.81\%) belonged to 18-30 years age-group while 105 and 62 participants were among 31-60 years and more than 60 years age-group. Of total, 186(58.13\%) were males and 134 $(41.87 \%)$ were females. In context to education, 8 were illiterate, 48 had primary education, 112 had completed schooling and 152 had graduated or above education. The optical aid usage by participants was assessed and revelations were: 107 and 49 were using only spectacles and contact lens respectively, 30 participants were used to wear both contact lens and spectacles while 134 (41.87\%) were not using any optical aid, as they didn't felt need for same.

The various symptoms reported by all study participants are listed in Table 2. The statistical significance of role of gender and age on occurrence of particular symptom was also analysed. The more common symptoms reported were: headache $(249,77.81 \%)$, burning eyes $(214,66.87 \%)$ and Dry eyes $(197,61.56 \%)$. Temporary difficulty in gaze from one distance to another and temporary blurred vision for few seconds were reported by $51.25 \%$ and $44.68 \%$ respectively. The role of gender was found statistically significant impact on occurrence of headache $(\mathrm{p}=0.0002)$ and temporary blurred vision $(\mathrm{p}=0.003)$. The association between gender and occurrence of other symptoms were statistically non-significant. The role of age was found statistically significant in occurrence of burning eyes $(p=0.001)$, dry eyes $(p=0.026)$, headache $(p=0.004)$, and double vision $(\mathrm{p}=0.008)$. The statistical association between age-group and occurrence of other symptoms was nonsignificant. (Table 2)

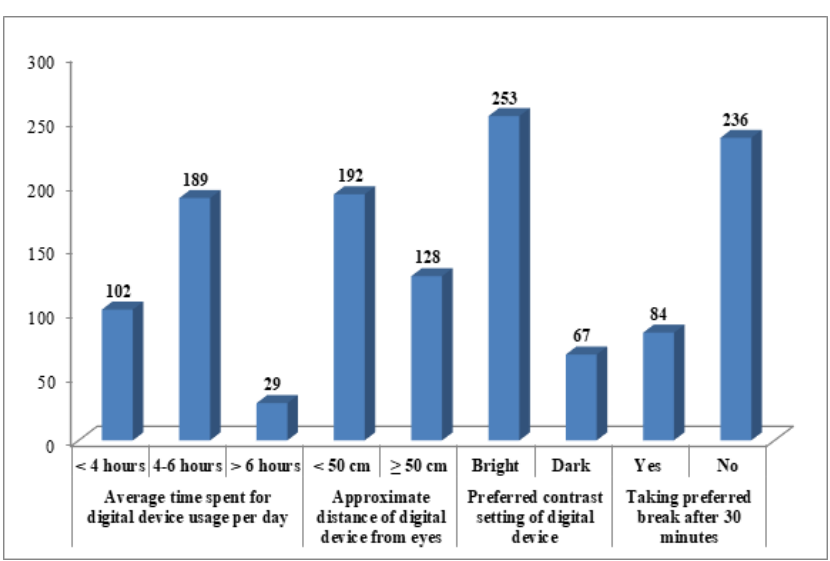

Fig. 1: Distribution of apparent risk factors for DES among study participants
Various apparent risk factors for occurrence of DES among study participants were also studied. On assessing the average time spent for digital device usage per day by patients, it was found that: $102(31.88 \%)$ used it for less than 4 hours per day while $189(59.06 \%$ ) and $29(9.06 \%)$ respectively used the digital device for 4-6 hours and more than 6 hours per day. Of total, 192(60\%) participants used the digital device with approximate screen distance less than $50 \mathrm{~cm}$. from eyes while remaining $40 \%$ used with approximate distance more than or equal to $50 \mathrm{~cm}$. The bright contrast setting was preferred by majority (253, $79.05 \%$ ) while remaining were used to prefer dark contrast setting. The ideal way of digital device usage, i.e. taking break after 30 minutes of continuous usage was preferred by only $84(26.25 \%)$ study participants. (Figure 1$)$

The association between various clinical symptoms of DES and risk factors for DES was evaluated. The chisquare test was selected as statistical parameter to decide significant association between two variables and if $p$ value for calculated chi-square is $<0.05$ was found, it suggests statistically significant association between two studied variable. It was revealed that red eyes, itchy eyes, headache and double vision were statistically significantly associated with average time spent for digital device usage. In context to approximate distance of digital device from eyes, the statistical significant association was found for burning eyes, dry eyes, red eyes, headache and difficulty in gaze from one distance to another. For another risk factor, i.e., taking preferred break after 30 minutes of continuous usage of digital device, all clinical symptoms revealed the statistically significant association except double vision. (Table 3)

The association between type of optical aid used by study participants and its effect on occurrence of particular clinical symptoms was analysed with odds' ratio. According to the usage pattern of optical aid, participants were divided in four group for this analysis as follows: Groups*: I use spectacles only, II - use contact lens only, III- use both contact lens and spectacles, IV - Does not use any optical aid. The group IV was taken as reference and the calculated value of odds' ratio for other groups suggest the comparative risk of occurrence of particular symptom. The clinical features like dry eyes, temporary difficulty in gaze from one distance to another and temporary blurred vision were comparatively revealed more risk with pattern of their optical aid usage than group IV participants. (Table 4)

\section{Discussion}

The concept of Digital Eye Strain (DES) is comparatively not much known to lay-men or to even other than ophthalmologist medical personnel. The present research tried to explore the various risk-factors' role in occurrence of this problem. The age-groups involved in this studies were $18-30(47.81 \%), 31-60(32.81 \%)$ and $>61$ years 
Table 1: Basic socio-demographic and general ophthalmic characteristics of study participants $(\mathrm{N}=320)$

\begin{tabular}{|c|c|c|c|}
\hline Variable & Characteristics & Frequency & Percentage (\%) \\
\hline & $18-30$ & 153 & 47.81 \\
\hline \multirow[t]{2}{*}{ Age-group (in completed years) } & $31-60$ & 105 & 32.81 \\
\hline & $>60$ & 62 & 19.38 \\
\hline \multirow{3}{*}{ Gender } & Male & 186 & 58.13 \\
\hline & Female & 134 & 41.87 \\
\hline & Illiterate & 8 & 2.50 \\
\hline \multirow{2}{*}{ Education } & Up to Primary & 48 & 15.0 \\
\hline & $\begin{array}{c}\text { Completed school (10/12 } \\
\text { years of schooling) }\end{array}$ & 112 & 35.0 \\
\hline \multirow{5}{*}{ Optical aid usage } & Graduate and above & 152 & 47.50 \\
\hline & Use of spectacles only & 107 & 33.44 \\
\hline & Use of contact lens only & 49 & 15.31 \\
\hline & $\begin{array}{c}\text { Use of both contact lens \& } \\
\text { spectacles }\end{array}$ & 30 & 9.38 \\
\hline & Does not use any optical aid & 134 & 41.87 \\
\hline
\end{tabular}

Table 2: Distribution of various symptoms of DES among study participants ${ }^{\#}$

\begin{tabular}{|c|c|c|c|c|c|c|c|c|}
\hline \multirow{2}{*}{ Symptoms } & \multirow{2}{*}{$\begin{array}{c}\text { Frequency } \\
(\%)\end{array}$} & \multicolumn{3}{|c|}{ Gender wise distribution } & \multicolumn{2}{|c|}{ Age-group wise distribution } & \multirow[b]{2}{*}{$\begin{array}{c}>60 \mathrm{yrs} \\
\mathrm{N}=62\end{array}$} & \multirow[b]{2}{*}{ p-value } \\
\hline & & $\begin{array}{c}\text { Male } \\
\mathrm{N}=186\end{array}$ & $\begin{array}{c}\text { Female } \\
N=134\end{array}$ & p-value & $\begin{array}{c}\text { 18-30 yrs } \\
\text { N=153 }\end{array}$ & $\begin{array}{c}\text { 31-60 yrs } \\
\text { N=105 }\end{array}$ & & \\
\hline $\begin{array}{l}\text { Burning } \\
\text { eyes }\end{array}$ & $214(66.87)$ & 129 & 85 & 0.267 & 117 & 63 & 34 & 0.001 \\
\hline Dry eyes & $197(61.56)$ & 116 & 81 & 0.728 & 104 & 54 & 39 & 0.026 \\
\hline Red eyes & $158(49.37)$ & 94 & 64 & 0.624 & 81 & 46 & 31 & 0.351 \\
\hline Itchy eyes & $93(29.06)$ & 52 & 41 & 0.608 & 51 & 30 & 12 & 0.122 \\
\hline Headache & $249(77.81)$ & 158 & 91 & 0.0002 & 131 & 76 & 42 & 0.004 \\
\hline $\begin{array}{l}\text { Double } \\
\text { vision }\end{array}$ & $24(7.5)$ & 13 & 11 & 0.683 & 6 & 8 & 10 & 0.008 \\
\hline $\begin{array}{l}\text { Temporary } \\
\text { Difficulty } \\
\text { in gaze } \\
\text { from one } \\
\text { distance to } \\
\text { another }\end{array}$ & $164(51.25)$ & 103 & 61 & 0.081 & 77 & 51 & 36 & 0.470 \\
\hline $\begin{array}{l}\text { Temporary } \\
\text { Blurred } \\
\text { vision }\end{array}$ & $143(44.68)$ & 96 & 47 & 0.0033 & 73 & 41 & 29 & 0.362 \\
\hline
\end{tabular}

\# Multiple responses allowed

(19.38\%) while gender distribution was - $58.13 \%$ males and $41.87 \%$ were females. The majority of the similar studies like conducted by Lograj M. et al., ${ }^{8}$ Shantakumari N. et al., ${ }^{3}$ Touma S RI et al $^{9}$ and Khan A A et al. ${ }^{7}$ were carried out in college or university students only targeting agegroup of 18-24 years. In present study, age-group $>18$ years were included which presents more appropriate statistical representation of population, as in today' era, all age-group people are using digital devices more frequently. In similar study conducted by Touma S. et al. ${ }^{9}$ at Beirut, Lebanon, the gender distribution was $55.4 \%$ males and $44.6 \%$ were females while Khan A. et al. ${ }^{7}$ in their study at Mangluru, Karnataka, India reported almost equal proportion of gender distribution.
In present study, the most common reported symptom by affected was Headache $(77.81 \%)$. Khan A et.al ${ }^{7}$ (India) and N. Shantakumari et al. ${ }^{3}$ in their similar study at Ajman, UAE also reported headache as most common symptom in $73.33 \%$ and $53.3 \%$ of participants respectively while Tawil L. ${ }^{10}$ in his similar study at Saudi Arabia reported $66.5 \%$ subjects suffered from Headache and $51.5 \%$ had dry eyes. In present study the prevalence of various symptoms of DES were: dry eyes (61.56\%), Red eyes (49.37\%), Itchy eyes (29.06\%), Double vision (7.5\%), Temporary Difficulty in gaze from one distance to another $(51.25 \%)$ and Temporary Blurred vision $(44.68 \%)$. Reddy $\mathrm{S}$ et al $^{11}$ in their study at Nepal found prevalence as follows: Headache $(19.7 \%)$, Dry eye $(13.6 \%)$, blurred vision $(10.2 \%)$, Red eye $(2.4 \%)$ and Double Vision $(0.3 \%)$ while in Ethiopia study 
Table 3: Association between risk factors and clinical symptoms

\begin{tabular}{|c|c|c|c|c|c|c|c|c|c|c|c|}
\hline \multirow[t]{2}{*}{ Symptoms } & \multirow[t]{2}{*}{ Frequency } & \multicolumn{4}{|c|}{$\begin{array}{l}\text { yverage time spent for digital device } \\
\text { usage per day }\end{array}$} & \multicolumn{3}{|c|}{$\begin{array}{l}\text { Approximate distance of } \\
\text { digital device from eyes }\end{array}$} & \multicolumn{3}{|c|}{$\begin{array}{l}\text { Taking preferred break after } \\
30 \text { minutes }\end{array}$} \\
\hline & & $\begin{array}{c}<4 \\
\text { hours } \\
\mathrm{N}=102\end{array}$ & $\begin{array}{c}\text { 4-6 } \\
\text { hours } \\
N=189\end{array}$ & $\begin{array}{c}>6 \\
\text { hours } \\
N=29\end{array}$ & $\underset{\text { value* }^{\mathbf{p}}}{ }$ & $\begin{array}{c}<50 \\
\mathrm{~cm} \\
\mathrm{~N}=192\end{array}$ & $\begin{array}{c}\geq 50 \\
\mathrm{~cm} \\
\mathrm{~N}=\mathbf{1 2 8}\end{array}$ & $\underset{\text { value* }^{\text {p }}}{ }$ & $\begin{array}{c}\text { Yes } \\
\mathbf{N}=84\end{array}$ & $\begin{array}{c}\text { No } \\
\mathbf{N}=236\end{array}$ & $\underset{\text { value }^{\text {p }}}{\text { p }}$ \\
\hline $\begin{array}{l}\text { Burning } \\
\text { eyes }\end{array}$ & 214 & 65 & 124 & 25 & 0.064 & 159 & 55 & 0.00 & 31 & 183 & 0.00 \\
\hline Dry eyes & 197 & 59 & 117 & 21 & 0.359 & 110 & 87 & 0.057 & 40 & 157 & 0.002 \\
\hline Red eyes & 158 & 40 & 97 & 21 & 0.004 & 99 & 59 & 0.05 & 24 & 134 & 0.00 \\
\hline Itchy eyes & 93 & 29 & 48 & 16 & 0.004 & 65 & 28 & 0.337 & 17 & 76 & 0.038 \\
\hline Headache & 249 & 86 & 139 & 24 & 0.02 & 159 & 90 & 0.008 & 43 & 206 & 0.00 \\
\hline $\begin{array}{l}\text { Double } \\
\text { vision }\end{array}$ & 24 & 07 & 10 & 07 & $0.005^{\#}$ & 14 & 10 & 0.862 & 09 & 15 & 0.192 \\
\hline $\begin{array}{l}\text { Temporary } \\
\text { Difficulty in } \\
\text { gaze from } \\
\text { one distance } \\
\text { to another }\end{array}$ & 164 & 55 & 90 & 19 & 0.161 & 89 & 75 & 0.031 & 54 & 110 & 0.0053 \\
\hline $\begin{array}{l}\text { Temporary } \\
\text { Blurred } \\
\text { vision }\end{array}$ & 143 & 49 & 77 & 17 & 0.139 & 84 & 59 & 0.679 & 46 & 97 & 0.03 \\
\hline
\end{tabular}

*Chi-square test applied, ${ }^{\#}$ Yates' correction done.

conducted by Dessie A et al. ${ }^{12}$ revealed the prevalence as follows: Blurred vision (62.60\%), Headache $(33.65 \%)$, Double Vision $(22.75 \%)$, Redness of eye $(40.28 \%)$ and Dry eyes $(22.27 \%)$. Altalhi A A et al. ${ }^{13}$ in their study at Saudi Arabia reported prevalence of symptoms as follow: Headache $(68 \%)$, Temporary long or short sightedness $(65 \%)$, itchy eye $(63 \%)$, burning sensation $(62 \%)$, blurred vision $(52 \%)$, Red eyes $(51 \%)$ and Dryness $(48 \%)$ The reported variation in symptoms of DES may be due to difference in age-group distribution as well as subject selection criteria. In current research, subjects were already diagnosed cases of DES while other have screened from a large group.

N. Shantakumari et al. ${ }^{3}$ reported statistical significance of distance of screen $<50 \mathrm{~cm}$ for occurrence of headache in DES while Khan AA et al. ${ }^{7}$ reported that $33\left(2 / 3^{r d}\right.$ of total) participants with digital device holding $<33 \mathrm{~cm}$ had DES score $>20$. Lograj $\mathrm{M}$ et al. ${ }^{8}$ reported that duration of hours of computers is significant for occurrence of Computer vision syndrome (CVS) and participants taking preferred break after every one hour had lesser symptoms of CVS. Similar findings were reported in present study.

Dessie et al. ${ }^{12}$ in their study found Calculated Odds' ratio significant for number of working hours $(>4.6)$ on computer/day while Reddy SC et al. ${ }^{11}$ in Nepal found duration of Computer use ( $>2$ hours/day) and wearing spectacles had statistically significant association with DES. Sawaya et al. ${ }^{9}$ in their study at Lebanon found significant adjusted Odds' ratio for participants using both glasses and contact lens. AI Tawil et al. ${ }^{10}$ reported regarding computer vision syndrome prevention, factors such as hours of use, screen distance, screen brightness, and room illumination showed statistically significant difference similar findings were reported in present study in terms of statistical significant association between presence of risk factors like higher average time spent for digital device usage per day, lesser approximate distance of digital device from eyes and not taking preferred break after 30 minutes and occurrence of symptoms of DES (Table 3).

\section{Conclusion}

Various symptoms of DES, prevalent among studied agegroup people were: Headache $(77.81 \%)$ dry eyes $(61.56 \%)$, Red eyes (49.37\%), Itchy eyes $(29.06 \%)$, Double vision (7.5\%), Temporary Difficulty in gaze from one distance to another (51.25\%) and Temporary Blurred vision (44.68\%). Red and itchy eyes, headache and double vision were statistically significantly associated with average time spent for digital device usage. Approximate distance of digital device from eyes revealed statistical significant association with burning, dry and red eyes, headache and difficulty in gaze from one distance to another. Taking preferred break after 30 minutes of continuous usage of digital device, all clinical symptoms revealed the statistically significant association except double vision. The clinical features like dry eyes, temporary difficulty in gaze from one distance to another and temporary blurred vision were comparatively revealed more risk with pattern of their optical aid usage than group IV (not using any optical aid) participants.

\section{Recommendations}

The prolonged usage of digital devices of various kinds is on increasing trend among all age-groups. The knowledge 
Table 4: Association between type of optical aid use and clinical symptoms of DES

\begin{tabular}{|c|c|c|c|c|}
\hline Symptoms & $\begin{array}{c}\text { Use of optical aid } \\
\text { Groups* }\end{array}$ & Symptom present & $\begin{array}{l}\text { Symptom } \\
\text { absent }\end{array}$ & Odds Ratio \\
\hline \multirow{4}{*}{ Burning eyes } & $\mathrm{I}(107)$ & 78 & 29 & 0.84 \\
\hline & II(49) & 33 & 16 & 1.10 \\
\hline & $\operatorname{III}(30)$ & 17 & 13 & 1.73 \\
\hline & IV(124) & 86 & 38 & 1 \\
\hline \multirow{4}{*}{ Dry eyes } & $\mathrm{I}(107)$ & 58 & 49 & 2.53 \\
\hline & II(49) & 26 & 23 & 2.65 \\
\hline & III(30) & 20 & 10 & 1.5 \\
\hline & IV(124) & 93 & 31 & 1 \\
\hline \multirow{4}{*}{ Red eyes } & $\mathrm{I}(107)$ & 58 & 49 & 0.59 \\
\hline & II(49) & 32 & 17 & 0.37 \\
\hline & $\operatorname{III}(30)$ & 18 & 12 & 0.47 \\
\hline & IV(124) & 51 & 73 & 1 \\
\hline \multirow{4}{*}{ Itchy eyes } & $\mathrm{I}(107)$ & 38 & 69 & 0.37 \\
\hline & II(49) & 22 & 27 & 0.25 \\
\hline & III(30) & 12 & 18 & 0.31 \\
\hline & IV(124) & 21 & 103 & 1 \\
\hline \multirow{4}{*}{ Headache } & $\mathrm{I}(107)$ & 89 & 18 & 0.80 \\
\hline & II(49) & 41 & 08 & 0.77 \\
\hline & $\operatorname{III}(30)$ & 20 & 10 & 1.98 \\
\hline & IV(124) & 99 & 25 & 1 \\
\hline \multirow{4}{*}{ Double vision } & $\mathrm{I}(107)$ & 13 & 94 & 0.12 \\
\hline & II(49) & 03 & 46 & 0.25 \\
\hline & $\operatorname{III}(30)$ & 06 & 24 & 0.07 \\
\hline & IV(124) & 02 & 122 & 1 \\
\hline \multirow{4}{*}{$\begin{array}{l}\text { Temporary Difficulty in } \\
\text { gaze from one distance to } \\
\text { another }\end{array}$} & $\mathrm{I}(107)$ & 63 & 44 & 0.85 \\
\hline & II(49) & 22 & 27 & 1.49 \\
\hline & III(30) & 11 & 19 & 2.1 \\
\hline & IV(124) & 68 & 56 & 1 \\
\hline \multirow{4}{*}{ Temporary Blurred vision } & $\mathrm{I}(107)$ & 48 & 59 & 1.24 \\
\hline & II(49) & 20 & 29 & 1.50 \\
\hline & $\mathrm{III}(30)$ & 12 & 18 & 1.55 \\
\hline & IV(124) & 63 & 61 & 1 \\
\hline
\end{tabular}

Use of optical aid - Groups*: I - use spectacles only, II - use contact lens only, III- use both contact lens and spectacles, IV - Does not use any optical aid

about prevention of risk factors of DES and correct technique in terms of distance of digital device from eyes, preferred break after certain time and preferred contrast setting shall be known to all people with alarming symptoms of DES. Accordingly health education and awareness activities shall be planned out by competent authorities of Health Department of Government.

\section{Source of Funding}

None.

\section{Conflict of Interest}

None.

\section{References}

1. Digital Eye train. [Online] North Carolina Optometric Society. North Carolina Optometric Society. Available from: https://www.nceyes.org/ digital-eye-strain.
2. American Optometric Association. Available from: https: //www.aoa.org/healthy-eyes/eye-and-vision-conditions/computervision-syndrome? $\mathrm{sso}=\mathrm{y}$.

3. Shantakumari N, Eldeeb R, Sreedharan J, Gopal K. Computer use and vision-related problems among university students in Ajman, United Arab Emirate. Ann Med Health Sci Res. 2014;4(2):258-63. 10:-10.4103/2/41-9248.129058.

4. Gowrisankaran S, Nahar NK, Hayes JR, Sheedy JE. Asthenopia and Blink Rate Under Visual and Cognitive Loads. Optom Vis Sci. 2012;89(1):97-104. doi:10.1097/opx.0b013e318236dd88.

5. Benedetto S, Drai-Zerbib V, Pedrotti M, Tissier G, Baccino T. E-Readers and Visual Fatigue. PLOS ONE. 2013;8:e83676. do1:10.1371/journal.pone.00836/6.

6. Mahajan BK. Methods in Biostatistics for Medical students and Research workers. 8th ed. Jaypee Publications;

7. Khan AA, Jain R, Hegde V, Bappal A, Rashmi S. Digital eye strain among undergraduate medical students in a tertiary eye care hospital of south India - A questionnaire based study. Indian J Clin Exp Ophthalmol. 2019;5(2):208-10.

8. Logaraj M, Madhupriya V, Hegde SK. Computer vision syndrome and associated factors among medical and engineering students in Chennai. Ann Med Health Sci Res. 2014;4(2):179-85. 10:-10.4103/2141-9248.129028. 
9. Musharrafieh U, Sawaya RT, Meski NE, Saba JB, Lahoud C, Saab $\mathrm{L}$, et al. Asthenopia among university students: The eye of the digital generation. J Fam Med Prim Care. 2020;9(8):3921. doi:10.4103/1/fmpc.jtmpc 340_20.

10. Tawil LA, Aldokhayel S, Zeitouni L, Qadoumi T, Hussein S, Ahamed SS. Prevalence of self reported computer vision syndrome symptoms and its associated factors among university students. Eur J Ophthalmol. 2020;30(1):189-95.

11. Reddy SC, Low CK, Lim YP, Low LL, Mardina F, Nursaleha MP. Computer vision syndrome: a study of knowledge and practices in university students. Nepal J Ophthalmol. 2013;5(2):161-8. doi:10.3126/nepjoph.v512.8707

12. Dessie A, Adane F, Nega A, Wami SD, Chercos DH. Computer Vision Syndrome and Associated Factors among Computer Users in Debre Tabor Town, Northwest Ethiopia. J Environ Public Health. 2018 :00:-10./15/20/8/410/590.
13. Altalhi AA, Khayyat W, Khojah O, Alsalmi M, Almarzouki H. Computer Vision Syndrome Among Health Sciences Students in Saudi Arabia: Prevalence and Risk Factors. Cureus. 2020;12(2). doi: $10.7759 /$ cureus. 7060

\section{Author biography}

Varsha M Modi, Assistant Professor

Cite this article: Modi VM. A study on digital eye strain among patients attending at one of the tertiary care hospitals of Saurashtra region, Gujarat. Indian J Clin Exp Ophthalmol 2021;7(2):392-398. 